\title{
Disputas en torno al trabajo juvenil y a la formación para el trabajo en los orígenes del peronismo
}

\author{
Romina De Luca \\ (Universidad Nacional de La Plata. \\ UBA. CONICET. \\ Centro de Estudios e Investigación \\ en Ciencias Sociales. Argentina) \\ Marina Kabat \\ (Universidad Nacional de La Plata. \\ UBA. CONICET-CEHR. \\ Centro de Estudios e Investigación \\ en Ciencias Sociales. Argentina)
}

\section{Resumen}

En este artículo analizamos la ley de trabajo de mujeres y menores de 1924 y sus consecuencias en materia educativa. Estudiamos las presiones empresariales por la modificación de dicha ley, en especial por la eliminación de las restricciones al empleo de menores. Por otra parte, analizamos la defensa sindical de dicha ley y las demandas obreras por una formación laboral de los jóvenes trabajadores. Intentamos ver cómo la disputa en torno a los límites a la explotación derivó en una discusión más general en torno a quién le incumbía el derecho de educar a las generaciones obreras.

Analizamos el conflicto a través de los reclamos de la Unión Industrial Argentina y las centrales obreras y focalizamos el caso de la industria del calzado donde el enfrentamiento por la regulación del trabajo de menores y su formación fue especialmente agudo.

\section{Palabras clave}

Educación Técnica - Peronismo - Obreros Industriales - Legislación Laboral - Conflicto Social.

\section{Summary}

This paper analyzes the 1924 law upon women and children work and the consequences that it had in the educational field. We also analyse the industrial's pressures for the modification of this law and for the elimination of the restrictions of 
child work. On the other hand, we look at the Union's defence of this legislation. This conflict turned out in a debate about who was responsible for the education of the young workers. We describe this dispute by analysing the review from the Argentinean Industrial Union and we describe the particular case of the shoe industry where this confrontation was particularly acute.

\section{Key words}

Technical Education - Industrial Workers - Labor Legislation - Peronismo - Social Conflict.

\section{Introducción}

En este artículo analizamos las iniciativas oficiales en torno a educación técnica que se implementan tras la sanción de la ley 11317 de 1924. En segundo lugar, estudiamos las presiones empresariales para la modificación de dicha ley. Para esto, examinamos la Revista de la Unión Industrial Argentina (UIA), Argentina Fabril, luego Revista de la Unión Industrial Argentina entre 1940 y 1945 y los reclamos de la Cámara de la Industria del Calzado $(\mathrm{ClC})$, rama donde el enfrentamiento por la regulación del trabajo de menores y su formación fue especialmente agudo y dio lugar a conflictos obrero-patronales. Finalmente estudiamos cómo, durante la década del cuarenta, se modificó progresivamente la ley de 1924 respondiendo a las presiones patronales, pero incorporando en forma secundaria algunas de las demandas obreras.

Consideramos importante estudiar este proceso para comprender los condicionantes de la legislación peronista en materia educativa y justipreciar sus elementos innovadores, sin sobredimensionar rupturas ni continuidades. Por último creemos necesario una mayor articulación entre el estudio de la historia de la educación y la del trabajo, vinculación a la que esperamos contribuir con este paper.

\section{Estado de la cuestión}

Los problemas del trabajo de menores y la formación profesional han sido abordados como aspectos independientes. El primero, ha sido poco estudiado en nuestro país. Los escasos análisis sobre esta problemática provienen de los historiadores del movimiento obrero. La mirada es demasiado general y tiende a limitarse a una historia de la legislación sobre trabajo infantil, algunos datos estadísticos y una recapitulación de las actividades con mayor incidencia del trabajo de menores. No hay estudios 
específicos sobre el período que nosotros abordamos. Las modificaciones a la ley 11317 no tienen un tratamiento detenido en los artículos dedicados a la temática del trabajo infantil (1).

En cambio, la educación profesional ha sido abordada, en forma predominante, por los historiadores o sociólogos de la educación. Puiggrós y Bernetti (2) reconstruyeron el proceso de uniformización de la educación técnica desarrollado, con fuerza, a partir de 1948 (3). Puiggrós y Bernetti niegan que el peronismo fuera un fenómeno educativo discriminador, visión que Tedesco (4) y Wemberg (5) tienen respecto de la Universidad Obrera Nacional (UON). Dentro de la misma corriente, Wiñar (6) la considera una respuesta demagógica cuyo principal objetivo sería la instalación de consenso en torno al proyecto de industrialización de los sectores dominantes. En este sentido, según Plotkin (7) la UON constituiría una forma de discriminación semejante a la promovida por los sectores conservadores (8).

En cambio, para Mollis (9) la Universidad constituía una iniciativa profundamente democratizante, en tanto brindaba la oportunidad de formación en el nivel superior a los trabajadores técnicos; el obrero podía convertirse en ingeniero. Puiggrós y Bernetti entienden que existiría en el peronismo una tendencia a vincular los distintos circuitos educativos (10). En relación a la UON han destacado sus rasgos de tipo escolar (11) y su estructura regionalizada.

Pineau y Dussel discuten con los trabajos historiográficos pioneros -Tedesco, Wiñar, Weinberg- la idea de improvisación en la política educativa peronista. Sostienen la existencia de una organicidad en las distintas reformas encaradas. Además no se trataría de un proyecto segregacionista (12). Pineau remarca cómo la Comisión Nacional de Aprendizaje y Orientación Profesional (CNAOP) y la UON promovieron socialmente actores antaño excluidos (13).

En síntesis, quienes consideran positiva la articulación entre educación y trabajo bajo el peronismo resaltan el desarrollo de la formación técnica y la democratización del sistema educativo ahora más inclusivo. Las críticas, en cambio, mayormente aluden a las formas de segregación o discriminación entre los circuitos educativos pensados para la clase obrera. Pero, en ningún caso es cuestionado el hecho de que el sistema de aprendizaje profesional convalidaba el empleo de menores en jornadas de trabajo de la misma duración que la de los obreros adultos. Al mismo tiempo, la mayoría de los estudios citados se concentran en reformas o planes y no en las prácticas educativas o las luchas a ellas asociadas. 


\section{La ley 11.317 y el desarrollo de la iniciativa estatal en materia de educación técnica: los años treinta}

La ley 11.317, sancionada en 1924 establecía, en su artículo quinto, que la jornada de trabajo de los menores de 18 años no podía exceder las 6 horas diarias ni 36 semanales. Prohibía también que mujeres y menores empleados en establecimientos tomaran al mismo tiempo tareas a domicilio. El trabajo de menores de 12 años estaba vedado y el de menores de 14, restringido a quienes se desempeñaran en compañía exclusiva de su familia. A su vez, se prohibía el trabajo de menores que no hubieran completado la educación primaria, pero el Ministerio de Menores podía autorizarlos a laborar cuando lo considerara indispensable para la subsistencia del menor o de su familia. Esta ley instituía el sistema de libretas de trabajo para los menores, que serían entregadas gratuitamente por el Registro Civil. El empresario estaba obligado a solicitar esta libreta en la cual tenía prohibido cualquier tipo de anotación adicional a las requeridas, especialmente si pudiera perjudicar al menor (14).

La creación de escuelas técnicas en todo el territorio se venía desarrollando en forma lenta desde la década del veinte. A partir de 1930 la creación de nuevas escuelas técnicas de oficios tendió a acelerarse. En ese contexto, en 1935 un primer informe sobre escuelas de artes y oficios de la Nación del inspector Juan José Gómez cuantificaba los establecimientos de todo el territorio: existían 35 escuelas repartidas entre Provincia de Buenos Aires (12), Santa Fe (4); Entre Ríos (2); Tucumán, Córdoba y San Luis (2 cada una). El resto de las provincias contaba con una. En ellas se repartía instrucción a 2.878 alumnos (15). La mayor parte de ellos se encontraban en las ciudades industriales. Los alumnos recibían durante el primer año una formación general organizada en tres talleres básicos: carpintería, herrería y mecánica. Luego debían elegir una orientación: carpintería, herrería o mecánica en todos los establecimientos, tonelería en las escuelas de las zonas viníferas, motoristas agrícolas, fundidores, o electricistas entre otras (16). La decisión de los alumnos se encontraba bastante sesgada: "de los 1.088 inscriptos desde segundo a cuarto año, en 1934, el 63,3\% corresponde al taller de mecánica, el $26,6 \%$ al de carpintería y sólo el $10,5 \%$ a los otros talleres" (17).

También había déficit en los equipamientos de las escuelas: había escuelas cuyas instalaciones resultaban anticuadas, con máquinas desgastadas y por lo tanto ineficientes e inseguras (18). Los establecimientos donde se impartía la orientación mecánica resultaban los más resentidos por ser los más masivos. 
También, había una imperiosa carencia de tornos y la escasez de cepillos para metales impedía el trabajo de piezas de mayor tamaño en buena parte de los establecimientos. En análoga situación se encontraban los talleres de fundición. Esa ausencia de equipamientos era el resultado de un déficit presupuestario. Entre 1930 y 1934 la matrícula se había duplicado y al presupuesto de $247.983 \$$, sólo se le habían adicionado 27.111 (19). Así las cosas, el funcionario recordaba:

"Manifesté en varios informes de visitas de inspección a escuelas de artes y oficios, durante el último año que en algunas de ellas, los directores se veían en aprietos para entretener -el término es exacto- a los alumnos de los talleres en los últimos días del mes, para evitar el gasto de materiales que ya no podrían ser costeados por agotamiento de las partidas" (20).

El análisis del número de egresados tampoco resultaba satisfactorio. La cantidad de graduados resultaba baja y "el porcentaje de egresados que consigue trabajo es mínimo, a pesar de todo, y no puede atribuirse a falta de preparación práctica" (21). Desde su perspectiva, esa situación sólo se podía explicar a partir de una cierta desidia del Estado que se encargaba de formar obreros y luego no los utilizaba.

En otro informe desde el Ministerio indicaron las ventajas que tenía la formación de futuros obreros por parte del Estado: respondían mejor al orden y en el espacio escolar se evitaba la contaminación de los jóvenes con las ideas apátridas profesadas por los obreros adultos. Señalan como una ventaja del sistema escolar:

"la educación y formación de esos futuros ciudadanos en ambientes de orden, sin el contacto prematuro con adultos que profesen y propaguen ideas contrarias a nuestras instituciones y al espíritu de nacionalidad" (22).

Tal como podemos ver, para los funcionarios la formación y capacitación de futuros obreros en la escuela los salvaguardaría de ideas anarquistas o socialistas. Asimismo, resultaba necesario focalizar los esfuerzos allí donde se concentrara la población obrera, es decir, en las grandes ciudades industriales. Porque además:

"Es corriente comprobar que en muchos de los talleres, fábricas y usinas en funcionamiento, los mejores puestos y los mayores jornales son para obreros extranjeros. Para esto es necesario poner a los operarios argentinos a la altura de la capacidad de 
aquéllos, porque sólo entonces podremos pretender que ocupen con todo derecho esas posiciones" (23).

Por los motivos expuestos presentaron un proyecto de ley para la creación de una escuela para la formación de obreros destinada a la industria del hierro en el barrio de Barracas, una para los obreros de la madera, en San Cristóbal, otra destinada a formar electricistas en Puerto Nuevo y, por último, la cuarta para obreros de la edificación en el barrio de Flores. En su artículo $3^{\circ}$, el proyecto establecía que además de la formación específica en el oficio, las escuelas debían brindar asignaturas de cultura general (24).

Se creó también una oficina de colocación de egresados de esas escuelas en reparticiones oficiales. De este modo, se obligaba a las dependencias nacionales y a las reparticiones autónomas a dar preferencia a los egresados de las cuatro nuevas escuelas capitalinas. El proyecto fue aprobado sin modificaciones con el número de Ley 12.234.

El 14 de diciembre de 1935 dando cumplimiento a la Ley 12.234 se aprobaron los planes de estudio de las cuatro escuelas. La Escuela Técnica de Oficios $n^{\circ} 1$ formaría obreros y capataces en los siguientes oficios: ajustadores, torneros, fresadores, matriceros, herreros de obra, herreros artísticos, calderos, carpinteros metálicos, fundidores y motoristas (25). También se desarrollaría un curso nocturno para herreros, mecánicos y motoristas que ya trabajaran en el oficio, tuvieran certificado de salud y cédula de identidad (26). La Escuela Técnica de Oficios $n^{\circ} 2$ formaría obreros carpinteros de obra, escaleristas, techistas, de pisos y parquets, carroceros, ebanistas, tallistas y escultores en madera. La Escuela Técnica de Oficios $n^{\circ} 3$, por su parte, desarrollaría su educación para electricistas, instaladores de usinas, de comunicaciones y cinematografía (27). Finalmente, la Escuela Técnica de Oficios $n^{\circ} 4$ capacitaría a obreros y capataces de albañilería, pintura y decoración, instalaciones sanitarias y capataces y sobrestantes de obras viales (28). Con posterioridad se fueron sancionando diversos programas de estudio como el del curso nocturno de electricidad de la Escuela Industrial de La Plata mediante el Decreto 6.504 de junio de 1938 o el plan para mecánicos motoristas agrícolas de la escuela de Chivilcoy (29) o, el general para escuelas industriales (Decreto $n^{\circ} 25.578$ de marzo de 1939).

En 1942 frente a las críticas de la UIA Berardone, un profesor de la Escuela Técnica $n^{\circ} 4$, acepta una posible extensión de la jornada de los menores, pero insiste en que ellos deben formarse en escuelas y no en la fábrica. El espacio escolar sería un ambiente mejor. Reproduciendo los fundamentos de la ley de creación de Escuelas técnicas de Oficio plantea que ellas evitaban: "el contacto prematuro con adultos que profesen y propaguen ideas contrarias a nuestras instituciones" (30). Por otra parte, 
señala que la formación en el taller sólo formaría al joven en la tarea que se le encomiende y "ésta lógicamente, será no la que convenga a su formación como obrero sino la que convenga, por su mayor rendimiento, a los intereses de la empresa puesto que se lo utilizará en trabajos en que por sus conocimientos resulte una utilidad y no un estorbo". De esta manera, el aprendizaje sería menos amplio, sistemático y profundo que el que podría adquirir en un establecimiento educativo. Como veremos, esta visión del trabajo juvenil en las fábricas concuerda con las críticas obreras al empleo de menores en tareas parcelarias que impedían el aprendizaje del oficio (31).

La legislación avanzó en la estructuración de un circuito de formación técnica en el ámbito educativo (32). La política de expansión se extendió durante toda la década y se profundizó en los cuarenta. Así, entre 1947 y 1951, el Estado creó -por lo menos- 78 escuelas fábrica, 103 de aprendizaje, 106 escuelas de medio turno, 304 de capacitación obrera para adultos y 78 de capacitación profesional para mujeres (33). Esas iniciativas estatales se sumaban a las de tipo privada, es decir, a la capacitación que ya se venía ejerciendo en academias, sindicatos o los cursos brindados por la Sociedad de Damas de Caridad, los Círculos de Obreros Católicos (34) y de la UIA.

\section{La posición de la Unión Industrial Argentina}

Aquí intentaremos ver la actitud de la UIA frente a Ley de Aprendizaje y la organización del trabajo industrial de menores. Para ello, analizamos la publicación oficial de la entidad durante el período 1940-1946, el momento de la campaña más álgida desarrollada por la institución. Intentaremos ver si las intervenciones de la entidad fueron contempladas en la legislación y cuál fue su forma de argumentación para alcanzar tal fin.

Ya en 1940 la UIA acusaba a la Ley 11.317 de causar el desempleo juvenil (35). Estudios de la entidad arrojaban que "de los 980.000 habitantes de 14 a 18 años con que cuenta el país (511.000 varones), sólo 63.000 de los primeros reciben instrucción" (36). El resto:

"Están agotándose prematuramente en el ocio y la vagancia, a la espera de que la edad militar, cuando han cumplido ya el servicio obligatorio, les brinde una remota y cada vez más problemática posibilidad de conseguir empleo o trabajo" (37).

En ese punto, afirmaban que nadie emplearía a un joven que se iniciara en el oficio a la edad en que "los auténticos obreros" eran ya oficiales 
constituidos y competentes. Aquí la edad parecía un elemento fundamental en la constitución de un buen o mal obrero:

"A un muchacho aprendiz de 14 a 15 años se le enseña, se le encamina, pero a uno de 22, díscolo, desmoralizado a fondo por la vida de holganza callejera que ha llevado e imbuido por contagio de extraviadas doctrinas ideológicas, no hay manera de hacerlo. Constituye un motivo de continuas discordias y un mal ejemplo para el resto del personal" (38).

Culpaban tanto al "régimen liberal" que había promulgado la Ley 11.317 como a "los legisladores marxistas". Estos últimos "en su sectario afán de destruir las fuentes de riqueza, le hicieron creer que impedía así la hipoteca moral y fisiológica de las futuras generaciones a la voracidad de la industria capitalista y sin ver que con eso hipotecaba al vicio, a la desocupación a la miseria, promulgó esta ley suicida del trabajo de los menores" (39). A ella hacían responsable de la decadencia económico-social del país. Resulta llamativo el nivel de desfachatez con que la entidad desarrolló su campaña en tanto no tenía ningún empacho en reconocer que el trabajo al que eran sometidos los menores podía causarles perjuicios a su salud. Sin embargo, llamaban a optar por el mal menor, en tanto:

"Habría que averiguar qué género de enfermedades hace más estragos en las clases indigentes, si las que adquiere el niño en el trabajo de la fábrica o las que adquiere en la vida ociosa a la que conduce fatalmente la desocupación" (40).

A pesar de ello, para la UIA resultaba imperioso derogar la Ley si no se quería prolongar la decadencia del país (41). En abril de 1941(42) no sólo plantean lo inapropiado de la Ley sino también de su encuadre con el conjunto del sistema educativo. La UIA entendía que la Ley era una copia foránea inadecuada para el medio ambiente argentino. La creación de escuelas taller, industriales y de oficios no tenía mayor sentido en nuestro país en tanto en el conjunto de la escuela primaria no cabía orientación alguna hacia un oficio manual. Si bien estimaban deseable la creación de un sistema educativo que proporcionara una preiniciación industrial y orientación vocacional, consideraban que ese proceso de formación ya se desarrollaba en el taller: "ante la carencia de centros de iniciación primaria para el joven obrero que trata de especializarse es necesario que el taller sea la escuela de formación del futuro obrero" (43). No podía existir una ley que transforme al aprendiz de elemento auxiliar a "causa de perturbación" (44) por ser su jornada diferenciada a la del obrero enseñante. Ese extrañamiento sólo 
había ayudado a que el joven se alejara de la fábrica convirtiéndose en un vagabundo. Una forma de revertirlo era que "aprendices mayores de 15 años, menores de 18 sujetaran su horario de trabajo como aprendices a la jornada legal y normal de los obreros calificados con quienes realizaban el aprendizaje". En sentido similar, el contrato de aprendizaje debía contemplar actividades especializadas en sentido educativo que no vulneraran los principios básicos del trabajo de menores en general. De esta forma, delineaban algunas directrices de cuál debería ser el espíritu de la nueva ley de trabajo de menores y aprendizaje.

En diciembre de 1941, cargaron una vez más contra la 11.317. En esta oportunidad publicaron un extenso trabajo del Ingeniero Gilli, director de la Escuela Industrial de la Nación "Oeste" de Buenos Aires (45). Gilli relata las tensiones entre iniciativas privadas y el Estado y narra cómo diversas industrias habían comenzado a formar aprendices "porque en general los obreros competentes no salen de las escuelas de artes y oficios, sino de los talleres donde han hecho sus aprendizajes no sólo técnico sino también disciplinado" (46). Tal como podemos ver, la entidad reitera su postura: los obreros deben educarse y formarse en la fábrica. Al respecto, Gilli afirmaba categóricamente:

"Querer centrar la formación de un obrero alrededor de la escuela, es pretender que la escuela asuma un rol rector en la creación y desarrollo de la industria misma. Ésta ha crecido, prosperado y propagado sin la intervención de la escuela profesional" (47).

La escuela "Oeste" había intentado acercar a los jóvenes al mundo del aprendizaje real, esto era, la fábrica articulando en su interior proyectos de formación junto a talleres de Avellaneda. La formación práctica de los jóvenes se desarrollaba en un taller bajo la forma de una pasantía. Pero como relata Gilli "la iniciativa tropezó con el obstáculo de la ley personificada en el Departamento Nacional de Trabajo que atendiendo a la letra legal rígida no veía estudiantes sino aprendices obligando en circunstancias a los empresarios a anotarlos en los registros de obreros y a poseer el correspondiente seguro" (48). Esta vez en boca de Gilli, la entidad reitera su malestar por la jornada de 6 hs. para menores de 18 años. Gilli añade que los menores debían tener un horario discontinuo con un descanso de $2 \mathrm{hs}$. al mediodía. Entonces, resultaba imposible compatibilizarlos con los dos turnos de 4 hs., mañana y tarde de los adultos. Así se obligaba al empresario a crear un horario especial para los menores. Esos dos problemas habrían terminando de alejar a los jóvenes de las fábricas y en consecuencia: 
"Al cerrarse el mercado de los aprendices aumentó simultáneamente el de los peones, es decir, el del trabajo inferior, con el envilecimiento consecutivo de su trabajo y de su estándar de vida" (49).

Va de suyo que en ese párrafo se reconoce que los menores-aprendices eran utilizados en forma productiva por los industriales. También que su trabajo era degradado y degradante. En ese punto, llamaba a no dejarse ganar la pulseada: los industriales no debían abandonar esa tarea a "la corriente burocrática de formación oficial". El eje de la discusión, entonces, giraba por la duración de la jornada de explotación de esos menores que resultaban más que rentables a los empresarios.

En febrero de 1942 (50), la UIA vuelve a ratificar su pedido de derogación de la Ley 11.317. En ese número, a los efectos de hacer ver a sus afiliados que no estaban solos publicaron notas periodísticas de los diarios La Razón y La Nación que apuntaban a la misma dirección. La entidad venía batallando por la implementación en forma plena de la Ley $\mathrm{n}^{\circ} 11.544$, sancionada el 17 de septiembre de 1929, que establecía en 8 hs. diarias o 48 semanales la duración de la jornada de trabajo "aunque no se persigan fines de lucro" (51). Desde la perspectiva de la UIA como el aprendizaje no era lucrativo no se entendía cómo se estipulaba una jornada reducida.

Un mes más tarde (52), la entidad informa que el Inspector General de Enseñanza Florencio Jaime se había contactado con la UIA para hacerles saber que el Ministro de Justicia e Instrucción le había encomendado realizar un informe sobre la valoración que hacían los empresarios de los egresados de escuelas técnicas. La entidad debía repartir entre los socios las encuestas del Ministerio aunque éste ya las había hecho llegar de antemano a las empresas.

Aprovechando la consulta, la UIA le hizo llegar una carta al Inspector a los efectos de hacerle conocer su opinión sobre el diagnóstico que ellos hacían de la enseñanza industrial. Dicho accionar lo hicieron público a los socios en su número de junio de 1942 sin más detalles sobre el contenido (53).

En el artículo "El aprendizaje industrial" recordaban que desde la sanción de la Ley, la entidad había dirigido numerosas peticiones a los poderes públicos "abogando por su reforma en la parte relativa a la jornada de los menores que no hayan cumplido la edad de 18 años" (54). Sin embargo, la entidad se cuidaba de explicitar su rechazo al conjunto de la ley. Desde su perspectiva: 
"A veces al poner por obra el laudable propósito de corregir las deficiencias se ha procedido sin hacer distinciones que habrían sido muy convenientes" (55).

El rechazo se concentraba en torno a la duración de la jornada de trabajo de los jóvenes entre los 16 y 18 años. La Unión Industrial afirmaba que para esa franja etaria se había fijado un criterio demasiado rígido. Pues la jornada laboral de 6 hs. hacía que se encontraran "serios inconvenientes para el aprendizaje industrial a causa de la dificultad que la jornada de seis horas opone al ingreso en equipos formados con los mayores" (56).

Asimismo, puntualizaban que:

"La labor de 8 hs. estaría supeditada a un riguroso examen médi$\mathrm{co}$, el cual, por lo demás siempre ha sido la regla [...] El mantenimiento del precepto actual [esto es las seis horas] de la ley vigente se explicaría si fuese una condición ineludible para obtener su finalidad. Desde que no lo es, su modificación se impone".

La reforma no beneficiaba sólo al mundo industrial. Más bien al conjunto de la sociedad:

"La reforma tendría más de un beneficio, entre los cuales se destacan el aprendizaje industrial de jóvenes argentinos y la disminución del número de los que por la disposición legal se inician en la vagancia" (57).

La publicación se volvió a referir a la problemática tres meses más tarde. En esta oportunidad, difundieron los resultados de un informe de la Inspección General de Enseñanza (58) solicitado por el Ex Ministro de Justicia e Instrucción Pública, Dr. Guillermo Rothe, a los efectos de evaluar el resultado de la enseñanza impartida en las escuelas industriales técnicas, de oficios y de artes y oficios así como también la inserción de los egresados en la industria privada. Sus resultados formarían parte de dos proyectos de ley que se enviarían al congreso: uno sobre "creación de nuevas escuelas industriales", el otro sobre "régimen de aprendizaje en las fábricas y talleres de la industria privada".

Los principales problemas que enumeró el equipo de trabajo era un deficitario número de escuelas en relación a los pedidos de inscripción: "En los últimos diez años solicitaron el ingreso en las escuelas industriales de la Nación 16.921 aspirantes y sólo consiguieron ser inscriptos 8.446”. La causa era la escasez de locales adecuados y el elevado costo de plantas y/o talleres industriales. Sin embargo, elogiaban las medidas públicas encaminadas a la creación de más escuelas para suplir esa demanda. 
En segundo lugar, las especialidades resultaban insuficientes. En ese momento, las escuelas contaban con cuatro grandes orientaciones -construcción, mecánica, electricidad y química-, debía promoverse otras "referentes a la industria de la fermentación, a la de tejidos y minería" (59).

En tercer término, las escuelas profesionales de mujeres no otorgaban una capacitación especial técnica a las mujeres que quisieran desarrollarse en la industria. Resultaba adecuado, entonces, crear "escuelas industriales femeninas".

La Comisión también veía necesario renovar el material de talleres y laboratorios, completar la dotación de herramientas y útiles. Pero llegados a este punto destacan una iniciativa que, considerando que se trataba de un informe cuyo objetivo era diagnosticar y proponer soluciones, tal vez propusieran extender: la inclusión en el plan anual de trabajos de los alumnos de las escuelas industriales la construcción de máquinas para los talleres de las escuelas. Una vez confeccionadas las máquinas se producía un intercambio de bienes entre las distintas escuelas acorde a los requerimientos de cada una. Esas tareas se encontraban diferenciadas de aquellas "metodizadas que responden a una finalidad educativa" (60). Así afirmaban que: "con esa iniciativa además de implicar una considerable economía para el Estado, contribuye al adiestramiento de los alumnos" (61).

En materia de ahorros, el informe también ponderaba el costo de esa modalidad educativa demandaban al Estado. Si bien el costo de los egresados en todo el país venía decreciendo en los últimos quinquenios, las escuelas públicas en pequeñas poblaciones "sin importancia industrial" arrojaban un valor mayor que el de las principales ciudades industriales.

Al final del informe se señala que "ya estaba previsto, y a pedido de los industriales, para conciliar intereses ascender a $8 \mathrm{hs}$. la jornada de trabajo de jóvenes de 16 y 17 años". A pesar del guiño, las controversias entre los industriales y lo legislado por el gobierno no se detuvieron. En el número de septiembre, la UIA intervenía para señalar las diferencias entre un contrato de aprendizaje y uno de trabajo (62). La entidad sostenía que a menudo se confundía y se tendían a equiparar la reglamentación del aprendizaje y el trabajo de menores. Un aprendiz no necesariamente tenía que ser un menor, cualquier obrero podía realizar un proceso a aprendizaje de un oficio en cualquier momento de su vida. La UIA sostenía que el código de trabajo de Francia y de España no dejaba lugar a dudas en torno a la definición de aprendiz:

"La obligación esencial está a cargo del empleador y tiene como objeto la enseñanza de un oficio o industria. La prestación de traba- 
jo constituye a su vez, simplemente, la forma, o una de las formas con que el aprendiz retribuye la prestación del patrón" (63).

De los argumentos vertidos por la UIA se desprende que el joven aprendiz no debía recibir remuneración alguna puesto que no estaría desarrollando un trabajo, aunque efectivamente lo hiciera, sino un proceso de formación y aprendizaje.

En el número de abril de 1944 (64) la UIA interviene nuevamente. Por un lado, informa que dos de sus miembros habían participado de una comisión especial encargada de evaluar los anteproyectos de Ley de trabajo de menores y aprendizaje. Se trataba de Torcuato Di Tella y Francisco Pratti. En segundo lugar, publicaron la postura que la UIA ya había esbozado en 1941. Entre los puntos centrales recordaban, en primer término, que el taller debía ser la escuela de formación del joven obrero del futuro. En segundo lugar, rechazaban que la Ley 11.317 obligara al menor de 18 años a trabajo en horario reducido y diferente del obrero de quien recibe la enseñanza. Eso resultaba un punto nodal, en tanto el menor mudaba "de elemento auxiliar que debería ser a causa de perturbación". Asimismo, ese aspecto "ha alejado al menor de la fábrica, fomentando su vagancia y hasta su delincuencia". Tal como vemos, para la UIA resultaba central la eliminación de la jornada de seis horas para los jóvenes menores de 18 años y mayores de 16 .

En agosto de 1944 (65), con motivo del proyecto de creación de nuevas escuelas de aprendizaje, emiten consideraciones generales sobre cuál debería ser el funcionamiento y la organización de esas escuelas. Manifiestan que si bien consideraban legítimo que el Estado legisle y cree escuelas el visto bueno debía pasar por las asociaciones gremiales patronales. Porque:

"Si los aprendices después de terminados sus estudios no encuentran buena acogida en los talleres, si el patrono no tiene fe en la finalidad de la escuela, la vida de ésta será mediocre y breve, terminará desapareciendo del todo" (66).

A sabiendas de que había un proyecto en marcha, la posición de la UIA aparece como una sutil advertencia. Asimismo, señalan que nadie más interesado que los empresarios mismos en tomar la educación profesional de sus obreros en sus manos no sólo porque así producirán mejor y ganarán la competencia sino también:

"El obrero instruido es más estable, no cambia de oficio, es más comprensivo y tiende a radicarse en la localidad en la que ha hecho el aprendizaje" (67). 
Otra de las ventajas de esa formación era su mayor eficiencia. Como la formación la realiza el personal técnico éste sabe qué materias son necesarias y cuáles superfluas. En septiembre retoman argumentos del número anterior (68). Allí se encargaron de atacar la reciente legislación promulgada. Desde su perspectiva, las escuelas de artes y oficios no servirían si su objetivo no era el de formar un aprendiz de determinado oficio sino generalidades. Al respecto indicaban:

"Una escuela que no sirva a oficio determinado, es una pseudoescuela que dará escasos frutos y en algunos casos frutos podridos, como los pedantes que se creen superiores al medio y que sólo un alto nivel de cultura técnica en el país logra ahogar" (69).

Para concluir, la Unión Industrial Argentina, en el número de abril de 1945, con algarabía, da a conocer a sus socios la modificación de la tan mentada ley 11.317 y su modificación, la 14.538. Conformes con su éxito dieron publicidad, en su totalidad, al nuevo decreto $n^{\circ} 6.648$.

\section{El conflicto en una rama económica: el caso de la industria del calzado}

No sólo la UIA se encargó de manifestar su rechazo frente a la Ley 11.317. También la CIC formula sus reclamos en nombre de una juventud que no podía ser abandonada en el vicio y la ignorancia. Así en una Editorial titulada "Otra prueba de que es necesaria la reforma de la ley de menores" la Cámara expone el problema de los menores que terminan estudios primarios que no tienen recursos para continuar sus estudios y que, en virtud de ley 11.317, se ven imposibilitados de trabajar:

"La calle, con las acechanzas que le son propias, en estos casos se agravan por la razón de la edad de quienes se ven condenados a vagar, entraña peligros que la sociedad y las autoridades no pueden dejar de contemplar" (70).

Por el contrario, los trabajadores del gremio llaman a defender la ley y responden a la campaña empresarial por su modificación. Así el periódico El obrero del Calzado publica el artículo "La Reforma de la ley 11.317 sería un espléndido negocio" (71). Allí cuestionan el estudio de la UIA sobre los jóvenes que no van a la escuela:

"Si alguien pensase que ante tal magnitud de esta suma de menores huérfanos de instrucción, a los propietarios de industria se les habrá ocurrida una medida salvadora para educar a esta infancia 
en peligro de malograrse, estaría totalmente equivocado. No efectuaron esta investigación con un objetivo humano, patriótico o social (...). Su propósito está movido sólo por una pasión de avidez inmoderada, tendiente a conseguir la modificación de la ley 11.317 de modo que se les permita explotar más extensamente a los menores adscriptos a sus fábricas y talleres".

Señalan que los empresarios debieran tener un fin humanitario, puesto que son los padres de estas criaturas quienes contribuyen a su riqueza. Sin embargo, con los datos publicados por la UIA, ésta perseguía otro fin:

“... Con ellos se busca impresionar al público con una cifra considerable de menores que suponen al margen de toda ocupación útil; y después inducirlo a creer que permanecen en esa situación porque la ley mencionada impide a los industriales adiestrarlos en el trabajo. De este modo hacen recaer todo ese mal sobre la ley $11.317 "$.

El periódico recalca que los empresarios cuestionan la ley en su núcleo humano que limita el trabajo de menores a seis horas velando por la salud intelectual y física de los aprendices y atendiendo al principio pedagógico de que la fatiga aniquila la capacidad de aprender. Señalan que es falso el argumento según el cual no pueden emplear jóvenes, dado que sus organizaciones fabriles están preparadas para las ocho horas. Al mismo tiempo citan la cantidad de permisos para trabajar otorgados por el Departamento Nacional de Trabajo a menores de edad: quince mil en 1937 y en 1938, dieciséis mil; estimaban que si se mantenía la tendencia ascendente en 1940 sería probable que los permisos se elevaran a veinte mil. De esta manera, los jóvenes sí eran empleados. El periódico añade que, si los empresarios no los contrataban en mayor número, era sólo porque ya no cabían más en sus establecimientos y que lo único que buscaban al impulsar la reforma de la ley 11.317 era el aumento de su horario de trabajo.

Un segundo artículo reitera estos argumentos. Insiste en que "no debe modificarse la ley de trabajo de los menores" (72) y añade que los empresarios son responsables por la situación que critican (la existencia de 700.000 jóvenes de 14 a 19 años que no estudian ni trabajan), puesto que ellos podrían emplear a los menores en dos turnos de cuatro horas cada uno, lo que no afectaría la estructura de trabajo en las fábricas.

Mientras permanece en vigencia, los trabajadores intentan velar por el cumplimiento de esta ley. Pero su violación encabeza la lista de las normativas infringidas por los industriales. Esto surge de la campaña de denuncias iniciada por el sindicato. Así por ejemplo en octubre de 1939, El 
obrero del calzado refiere a cinco casas que habían sido multadas por el Departamento Nacional del Trabajo por violar dicha ley. Entre ellas figuraba el establecimiento de Del Río, presidente de la CIC (73). En marzo de 1941 el sindicato afirmaba:

"Es indispensable lograr el cumplimiento de la ley 11.317, que protege el trabajo de los menores. A nuestro gremio se halla incorporado un vasto sector juvenil que trabaja en condiciones terribles, con salarios miserables y sin ninguna protección. El cumplimiento de la ley 11.317 debe ser reclamado, pues, como peldaños hacia mejorar las condiciones de vida y de trabajo de los jóvenes obreros del calzado, cuya suerte si no preocupa a los patrones debe ser motivo de constante atención de todos nosotros" (74).

Por su parte, la Cámara acusaba a la ley 11.317 de entorpecer e imposibilitar la formación profesional y el aprendizaje. Al impedir, supuestamente, el empleo de jóvenes, aquellos no se formarían, por lo que habrían comenzado a escasear los obreros especializados o calificados. Sin embargo, el sindicato describe una situación muy diferente. Los jóvenes eran empleados en grandes cantidades, pero en tareas parcelarias que no los acercaban en nada al aprendizaje de un oficio. Tanto las mujeres como los jóvenes: "se ven frente al grave problema de no vislumbrar un horizonte halagüeño para su futuro que les permita capacitarse técnicamente para las distintas ramas de la industria y poder adquirir los conocimientos técnicos y prácticos que, factor indispensable para aprender el oficio y ser un obrero especialista. $Y$ esto ocurre dado el gran desarrollo alcanzado por la manufacturación del calzado (...) por la racionalización que en su desmedido afán de lucro no tiene reparo en esclavizar a jóvenes en minúsculas operaciones, con el solo propósito de poder alcanzar mayores beneficios de sus ya cuantiosas ganancias" (75).

De este modo, la enseñanza técnica y la promoción dentro de la industria es vista por los obreros como un derecho que les es negado a jóvenes y mujeres a quienes "se les pagan salarios miserables que no alcanzan a $2 \$$ diarios, sin otro norte para su porvenir que el ya expresado con anterioridad". En cuanto a los menores de ambos sexos, se les hace trabajar ocho horas a la par de los adultos, "pavoroso drama que se extiende como una plaga en la industria es que el sindicato iniciara la agitación necesaria (...) a los efectos de lograr para los jóvenes un estándar de vida más decoroso" (76). Por eso, el sindicato convoca una asamblea de jóvenes aprendices, para organizarse, lograr el cumplimiento de la ley 113.17, "por el derecho al aprendizaje y mejores salarios". 
Fue en este contexto en el que se inaugura, el 7 de septiembre de 1943, la escuela de la CIC. Se afirma que la escuela resolvería la escasez de obreros especializados. Se aduce, por ejemplo que, como consecuencia de la Ley 11.317, "escasea la mano de obra especializada y también el aprendiz" (77).

Se consideraba, además, que las escuelas técnicas existentes no cubrían las necesidades reales. Sus egresados "tienen generalmente un criterio erróneo de cuál debe ser su ubicación inicial y el rol que deben desempeñar en las industrias" (78). No quieren ser capataces considerando a este puesto como inferior al de los administrativos. Por último, tendrían "excesivas pretensiones remunerativas en relación con sus conocimientos".

Al crear una escuela de la industria, por una parte, se brindarían los conocimientos específicos que la rama demandaba. En segundo lugar, esta formación especializada y acotada a estas necesidades volvería a esta mano de obra más económica que aquella preparada en escuelas técnicas de formación más amplia o general.

Resulta significativo que los cursos de capacitación ofrecidos por la Cámara se limitasen a las tareas de corte y modelaje. Precisamente estas tareas no se habían visto tan expuestas al proceso de descalificación producto de los cambios técnicos en la rama. Al estar relativamente protegidas de este proceso de descalificación, en estas tareas los obreros mantenían el control del aprendizaje y, por ende, del ingreso al gremio. El control del acceso al oficio por medio del aprendizaje era uno de los mecanismos por los cuales se restringía el empleo femenino. Pero, además, el aprendizaje guiado por los mismos obreros implicaba no sólo la enseñanza de las tareas laborales, sino también el aleccionamiento sobre pautas sindicales, como el límite de las tareas diarias que era importante en la sección de cortado.

Por un lado, la escuela creada por los empresarios evita ser demasiado disruptiva e inscribe sólo varones en sus cursos. Pero, por otra parte, intenta inculcar pautas laborales, que eran resistidas por los trabajadores. En ese sentido de la descripción del programa y los métodos de enseñanza se observa una insistencia en dos puntos problemáticos: el mayor aprovechamiento de los materiales y la velocidad.

El número de inscriptos en esta escuela en los tres años de su funcionamiento rondará el centenar de estudiantes, lo que contrasta con la cantidad de menores empleados en la industria (3.700 en 1943 y 7.600 en 1949). Lo que nuevamente indica la ausencia de una demanda de calificaciones especiales en la gran mayoría de los menores contratados. Este bajo número de estudiantes es una de las causas por las cuales posteriormente la Comisión Nacional de Aprendizaje y Orientación Profesional les negará su reconocimiento (79). 


\section{Las reformas}

La campaña contra la ley 11.317 surte resultado y, en 1943, llega la primera modificación parcial con el decreto 6.289 cuyo artículo $1^{\circ}$ establecía que los mayores de 14 años y menores de 18 podían trabajar por cuenta ajena hasta 8 hs. por semana o 48 semanales (80). Así se ponía fin a lo pautado por el artículo $5^{\circ}$ de la Ley de trabajo de menores. Asimismo, días más tarde, se promulgó el Decreto 7.646 en él se dejaba constancia que la empleabilidad de esos menores no debía verse afectada por la incompletitud de la instrucción primaria. A tales efectos, los jóvenes debían asistir a las escuelas complementarias para finalizar la obligatoriedad escolar, situación que debía ser constatada y registrada por el patrón o empleador (81).

En los considerandos de la ley se establecía que la enseñanza del trabajo constituía una de las formas de aumentar el nivel cultural y técnico de los obreros y con ello la producción. Para la consecución de tal fin, resultaba necesaria la estructuración de un régimen organizado de aprendizaje por parte del Estado que hasta ese momento se habría limitado al control y a la vigilancia (82). Por ello, la Ley establecía que correspondía al Estado la vigilancia, contralor y dirección del trabajo y aprendizaje de los menores de 14 a 18 años (art. $1^{\circ}$ ). Asimismo, se establecían tres categorías para el desempeño de los menores: aprendiz, menor ayudante obrero y menor instruido $\left(\right.$ art. $2^{\circ}$ ). Dentro del aprendizaje se incluía a todo régimen de trabajo cuya organización le permitiera al menor asegurarse de la enseñanza de un oficio en donde los trabajos realizados estuvieran graduados y metodizados y la enseñanza teórica apareciera como un complemento del trabajo ejecutado $\left(\right.$ art. $\left.4^{\circ}\right)$. En relación a la duración del tiempo de trabajo se establecía que los menores de entre 14 y 16 años no podrían trabajar más de 4 horas diarias o 24 semanales, por su parte los menores mayores de 16 años y menores de 18 podrían hacerlo hasta 8 horas diarias o 48 horas semanales (83). Tal como podemos ver, el decreto de junio de 1944 alteraba así los límites a la jornada laboral de los menores de 18 años establecidos en el artículo $5^{\circ}$ de la Ley 11.317. También se establecía un fondo denominado "caja de aprendizaje y trabajo de los menores" que estaba compuesto por fondos de la Nación, donaciones y legados de personas o empresas, multas aplicadas por el incumplimiento de la Ley así como un impuesto especial del $1 \%$ del sueldo pagadero por cada una de las empresas que empleara más de 5 menores $\left(\operatorname{art.~} 4^{\circ}\right)$. Además, se establecía un impuesto especial para aquellas empresas que emplearan menores sin haber organizado y metodizado el trabajo bajo la forma de un régimen de aprendizaje.

Poco menos de un año más tarde, en abril de 1945, se procedió a modificar algunos artículos del decreto 14.538 a través de la sanción del 
decreto-ley $n^{\circ}$ 6.648. Según se establecía en los considerandos de la Ley se atendía a las presentaciones formuladas por la UIA, la CIC así como también a las realizadas por numerosas firmas particulares. Básicamente, se ratificó la jornada de $8 \mathrm{hs}$. para mayores de 16 (artículo $29^{\circ}$ ) y se disminuyeron las tasas fijadas en materia de impuestos al aprendizaje (84). Asimismo, también se establecía la organización de cursos de pre-aprendizaje en las escuelas de medio turno primarias para los alumnos mayores a cuarto grado (art. $16^{\circ}$ ) y para adultos mayores que buscaran perfeccionarse (art. $15^{\circ}$ ).

Según el segundo artículo del decreto, los jóvenes menores quedarían encuadrados en tres categorías: aprendiz (aquellos que complementaban su trabajo con cursos de aprendizaje); menor ayudante obrero (aquellos que trabajaran sin estar sometidos a un régimen organizado de aprendizaje) y menor instruido (aquellos que ya hubieran concluido una escuela profesional o curso de aprendizaje). Los menores instruidos "serán considerados como obreros adultos para el trabajo u oficio correspondiente a su especialización, sin más excepción que la prohibición de trabajo nocturno y en industrias insalubres o que afecten su moralidad".

Se consideraría aprendizaje todo trabajo en el cual se asegurase al menor un aprendizaje efectivo de un oficio, donde los trabajos tuvieran una graduación y metodización a la vez que contemplaran la edad y fuerza del menor y, finalmente, que la enseñanza teórica impartida complementara el trabajo ejecutado.

La proporción de aprendices sobre el total del personal ocupado no podía superar el $30 \%$ respecto de los primeros 20 obreros, ni el $10 \%$ sobre el excedente. Las excepciones a esta cláusula debían ser negociadas en comisiones paritarias. La jornada de los menores jóvenes de entre 16 y 18 años no podía superar las 8 horas diarias ni las 48 horas semanales. Aquellos que tuvieran entre 14 y 16 años podían trabajar hasta 4 horas diarias debiendo concurrir en el turno libre a la escuela primaria, sino la tuvieran completa o a la una escuela profesional.

La Dirección General de Aprendizaje y Trabajo de Menores proveería gratuitamente de una libreta a todos los menores comprendidos por el decreto. En ella se consignaría el nombre, edad, ocupación, horario de trabajo del niño, así como el nombre, profesión y domicilio de sus padres. También debía constar si el menor había completado los estudios primarios. El empleador de menores debía exigirles la libreta y anotar en ella la categoría en la que trabajaba el joven, estando prohibida toda otra anotación "especialmente las que, de una u otra firma, pudieran resultar perjudiciales".

Sin embargo, pronto se suscitan conflictos en torno al financiamiento de las actividades encaradas por la comisión Nacional de Aprendizaje y 
Orientación Profesional. El artículo $43^{\circ}$ del decreto fijaba la creación de un impuesto para aprendizaje del diez por mil sobre el total de los sueldos, salarios, jornales y remuneraciones pagadas al personal ocupado en los establecimientos industriales. Este impuesto podía reducirse al dos por mil cuando los contribuyentes tuvieran organizados cursos de aprendizaje para menores de 18 años, fueran instituciones propias o en colaboración organizadas por asociaciones o cámaras, siempre que los cursos estuvieran aprobados por la Comisión Nacional de Aprendizaje y Orientación Profesional. Esto como ya comentamos dio lugar al conflicto en torno a la escuela de la CIC que terminó con su cierre.

De acuerdo al artículo $6^{\circ}$, la aprobación de las escuelas y cursos dependía de que la organización, funcionamiento y planes se ajustaran a los organizados por la CNAOP; que los presupuestos de sueldos y gastos fueran análogos a los de aquella y que el número de alumnos con asistencia obligatoria no fuera inferior al de aprendices ocupados por los establecimientos.

Un segundo decreto reglamentó las condiciones laborales vigentes para los menores. Así, el decreto 32412/45 establecía que los aprendices no ganaran en el primer año menos del $30 \%$ de un peón de la industria en la que se desempeñaran y no menos del $50 \%$ durante el segundo año. Por su parte, un menor ayudante obrero de 14 a 16 años no ganaría menos del $50 \%$ y si tuviera entre 16 a 18 , no menos del $70 \%$ de lo que gane el peón adulto.

Dentro de los 30 días de haber iniciado el aprendizaje, los menores gestionarían su libreta de ahorros de la Caja Nacional de Seguro y Ahorro Postal. El empleador depositaría en la cuenta el $10 \%$ del salario del menor. El mismo tenía derecho a vacaciones pagas, pero durante ellas no podía efectuar trabajo para sí o para otros.

Finalmente, en diciembre de 1945 en la legislación se determinan los beneficios que gozarían los menores de entre 14 y 18 años que trabajaran en talleres o establecimientos industriales (85). Por decreto se establece que los aprendices no ganarían en el primer año menos del $30 \%$ de un peón de la industria en la que se desempeñaran y no menos del $50 \%$ durante el segundo año. Por su parte, un menor ayudante obrero de 14 a 16 años no ganaría menos del $50 \%$ y si tuviera entre 16 a 18 , no menos del $70 \%$ de lo que gane el peón adulto.

\section{Conclusiones provisorias}

Hemos examinado la recepción que de la legislación sobre trabajo de mujeres, menores y aprendices hizo el empresariado industrial y cuáles 
eran los reclamos obreros y patronales. Consideramos que estas demandas actúan como condicionamientos de las reformas legislativas de mediados de la década del ' 40 y de la estructuración del circuito técnico que llevó adelante el peronismo en el gobierno.

Los empresarios se oponían a la limitación de la jornada de trabajo de menores y mujeres impuestas por la Ley 11.317. Esa restricción no constituía un mayor problema a comienzos de los treinta en un contexto de elevado desempleo. Sin embargo, a inicios de los cuarenta comienza a constituir un problema cuando la economía funciona en un marco cercano al pleno empleo. La UIA también reivindicaba la fábrica como el espacio de formación por excelencia cuestionando las iniciativas oficiales de educación técnica.

Entre 1940 y 1944 encontramos por lo menos doce artículos en su publicación mensual lidiando por la derogación de la Ley. No es menor el número de artículos relativos al tema en la Revista de la CIC. Como pudimos rastrear, la presión patronal llegó a tal punto que, desde el Ministerio de Justicia e Instrucción Pública, se inició una serie de consultas a los efectos de encontrar una posible solución. Varias fuentes indican que pronto se contempló transigir frente al reclamo del incremento de la jornada. En cambio, la pertinencia de la formación técnica en escuelas públicas fue defendida. Según funcionarios y docentes, la instrucción escolar aseguraba mayor sistematicidad, amplitud de los conocimientos y preservaba a los jóvenes de un temprano contacto con ideologías visualizadas como peligrosas.

Finalmente, los empresarios lograron su principal demanda, la derogación del artículo $5^{\circ}$ de la 11.317. En marzo de 1945 se sancionó el Decreto-Ley $6.648 / 45$ que en su artículo $29^{\circ}$ reemplazó la jornada de 6 horas por la de 8 horas para los menores de 18 años. El Estado continuó ampliando la red de escuelas técnicas, dotándolas de una organicidad de la que antes carecían. Por su parte, los trabajadores obtuvieron una satisfacción parcial de sus reclamos. Dentro de la nueva legislación sobre el trabajo de menores se incorporaron en forma secundaria algunos de los reclamos obreros, vinculados a salarios de los menores y proporción de aprendices sobre el número total de trabajadores, entre otros. En distintas ramas, como la industria del calzado, posteriores regulaciones introducidas en los convenios de trabajo profundizaron esto, por la vía de regimentar un ascenso automático por antigüedad (86). En cambio, el reclamo de restituir la jornada de 6 horas para los menores será desoída (87).

En la forma en que se resuelve el conflicto se satisface el interés principal de los industriales, junto a reclamos parciales de los obreros, mientras que el Estado acrecienta su participación en la formación técnica de los 
jóvenes. Establecer en qué medida esta ampliación de las atribuciones públicas responde a la actuación del Estado como representante colectivo de la burguesía, o a demandas particulares de obreros e industriales es un interrogante que queda abierto a futuras indagaciones.

\section{Notas Bibliográficas}

(1) Suriano, J. (2007) “El trabajo infantil”, en Torrado, S Población y bienestar en la Argentina del primero al segundo centenario, Tomo 2, Edhasa, Buenos Aires. Suriano, J. (1990) "Niños trabajadores. Una aproximación al trabajo infantil en la industria porteña a principios de siglo", en Armus, D. (comp.) Mundo urbano y cultura popular, Sudamericana, Buenos Aires. Pagani, E. y Alcaraz, M. V. (1991) Mercado laboral del menor (1900-1940), CEAL, Buenos Aires.

(2) Puiggrós, A. y Bernetti, J. L. (2003) Peronismo: cultura política y educación (1945-1955). Buenos Aires, Galerna.

(3) Tedesco J. C. (1980).

(4) Weimberg, G. (1985).

(5) Wiñar, D. (1979).

(6) Plotkin, M. (1995).

(7) Ibidem, p. 91.

(8) Mollis, M. (1991).

(9) Puiggrós, A. y Bernetti, J. L. (2003). p. 260. Esta posición es compartida por: Balduzzi, J. (1988).

(10) Ibidem, p. 270.

(11) Ibidem, p. 161.

(12) Pineau, p. (1991).

(13) Anales de legislación argentina. Complemento, año 1920-1940, (1953) Editorial La Ley, Buenos Aires, 1953, pp. 191 y ss.

(14) Ministerio de Justicia e Instrucción Pública (1935) Escuelas de Artes y Oficios. Informe elevado por intermedio de la Inspección General de Enseñanza, del inspector de esos establecimientos, Ing. Juan José Gómez, Buenos Aires, p. 5.

(15) Ídem, p. 10.

(16) Ibidem.

(17) Ídem, p. 13.

(18) Ídem, p. 14.

(19) Ídem, p. 16.

(20) Ídem, p. 19.

(21) Ministerio de Justicia y Educación (1935) Creación, fundación, organización y plan de estudios de cuatro escuelas técnicas de oficios, Buenos Aires, p. 6.

(22) Ídem, p. 6.

(23) Ídem, p. 7.

(24) Ídem, p. 11. 
(25) Ídem, p. 21.

(26) Ídem, p. 15.

(27 Luego funcionaron también cursos de aparadores de calzado.

(28) Decreto $n^{\circ} 6.377$ sancionado por la Dirección de Instrucción Pública el 15 de junio de 1938.

(29) El mismo texto es recogido también por: Ministerio de Justicia y Educación (1935) Creación. Op. Cit.

(30) Berardone, J. (1942) La escuela técnica de oficios y proyecto de reorganización de la Escuela Técnica de Oficios $n^{\circ} 4$ de la Nación, Buenos Aires, p. 10.

(31) Pineau sostiene que, hasta 1940, la estructuración del circuito de educación técnica se realizó en forma desarticulada y desorganizada. Recién a partir de 1944 con la creación de la CNAOP se revertiría esa situación. Pineau, P. (1991).

(32) Santos Martínez, P. (1979) La nueva Argentina, 1946-1955, Tomo I, Buenos Aires, p. 207.

(33) Ver Pascucci (2007).

(34) Argentina Fabril (AF), (marzo 1940), Año LIII, № 855.

(35) Ídem, p. 17. A partir de aquí, todos los entrecomillados se corresponden con citas textuales del artículo de referencia.

(36) Ibidem.

(37) Ibidem.

(38) Ibidem.

(39) Ibidem.

(40) Ibidem.

(41) AF, (julio de 1940), Año LIII, NNo 859.

(42) AF, (abril de 1941), Año LIV, Nº 868.

(43) A partir de ahora todos los entrecomillados corresponden al número de abril de 1941.

(44) Ibidem.

(45) AF (diciembre de 1941), Año LIV, No 876.

(46) Ídem, p. 24.

(47) Ibidem.

(48) Ibidem.

(49) Ibidem.

(50) AF, (febrero de 1942), Año LV, № 878.

(51) Anales de Legislación Nacional, Tomo 1920-1940, p. 226.

(52) AF, (marzo de 1942), Año LV, № 879.

(53) AF, (junio de 1942), Año LV, No 882.

(54) AF, (marzo de 1943), Año LVI, № 891. A partir de aquí, todos los entrecomillados se corresponden con el artículo citado.

(55) Ídem.

(56) Ídem. 
(57) Ídem.

(58) AF, (junio de 1943), Año LVI, No 894, p. 55-59. A partir de aquí -salvo que se indique lo contrario- todos los entrecomillados se corresponden con este número.

(59) Ídem.

(60) Ídem.

(61) Ídem.

(62) AF, (septiembre de 1943), Año LVI, No 897, p. 59-61.

(63) Ídem.

(64) A partir del año 1944 la revista cambia su nombre sin alterar su numeración. Ahora se conocía como Revista de la Unión Industrial Argentina (RUIA). El número de referencia es el № 904, del año LVII, abril de 1944. Hasta nuevo aviso todos los entrecomillados se extraen de este número.

(65) RUIA (agosto de 1944), Año LVII, № 908. Se exponen dos casos de escuelas de aprendices en Europa Central.

(66) Ídem.

(67) Ídem.

(68) RUIA (septiembre de 1944), Año LVII, № 909.

(69) Ídem.

(70) La industria argentina del calzado (LIAC), (febrero de 1940), p. 11.

(71) El obrero del calzado (EOC) (octubre de 1940): № 42, pp. 2 y 3 . Hasta nueva mención los entrecomillados corresponden a este artículo. También afirma que en Capital trabajaban más de los 10.000 menores contabilizados por la UIA.

(72) EOC (agosto de 1943), N 53, p. 8.

(73) EOC (octubre de 1939), № 40. El sindicato acusa a los empresarios desnaturalizar las leyes sociales mediante su incumplimiento generalizado. Ver: Del taller a la fábrica. Proceso de trabajo, industria y clase obrera en la rama del calzado 1880-1940. Buenos Aires, Ediciones RyR, 2005.

(74) EOC (marzo de 1941), No 44, p. 1.

(75) Ídem, p.2.

(76) EOC (marzo de 1941), № 44 p. 5. A partir de aquí, los entrecomillados corresponden con este artículo.

(77) LIAC, (mayo de 1946), p. 29.

(78) LIAC, (marzo de 1944), p. 19. En LIAC, de mayo de 1945, p. 24 cuestionan la excesiva formación de ingenieros y la falta de técnicos de formación más acotada. A partir de aquí, los entrecomillados corresponden con este artículo.

(79) Entre 1946 y 1947 se produjo un conflicto por esta falta de reconocimiento. Los empresarios buscaban el reconocimiento estatal de su escuela y, merced al mismo, una reducción del impuesto para el aprendizaje industrial que los afiliados de la Cámara debían pagar. Cuando esto no fue conseguido la escuela fue cerrada. Ver: LIAC, agosto de 1947.

(80) Anales de Legislación Nacional, (1943) Tomo III, p. 312-313. 
(81) Ídem, p. 333.

(82) Ídem, p. 332.

(83) Ídem, p. 335. Artículos 26 y 29 respectivamente.

(84) El decreto completo fue publicado en la RUIA (abril de 1945), Año LVIII, $\mathrm{N}^{\circ} 916$.

(85) Se trata del decreto $n^{\circ} 32.412$ del 17 de diciembre de 1945, en Anales de Legislación Argentina (1945), Tomo V.

(86) En la industria del calzado dicho escalafón se establece en el convenio de 1949 y es fuertemente criticado por los industriales Liac, enero de 1949, pp. 20-21.

(87) Un petitorio con este reclamo puede verse en: CGT, $\mathrm{n}^{\circ} 557,1 / 10 / 1946$, p. 12.

\section{Referencias Bibliográficas}

- Balduzzi, J. (1988) "Peronismo, saber y poder" en Puiggrós A. Hacia una pedagogía de la imaginación de América Latina. Buenos Aires, Contrapunto.

- Kabat, M. (2005) Del taller a la fábrica. Proceso de trabajo, industria y clase obrera en la rama del calzado 1880-1940. Buenos Aires, Ediciones RyR.

- Mollis, M. (1991) "La historia de la Universidad Tecnológica Nacional: una universidad para hombres y mujeres que trabajan" en Revista Educaçao y sociedade, Año 12, n 39, Campiñas.

- Pagani, E. y Alcaraz, M. V. (1991) Mercado laboral del menor (1900-1940). Buenos Aires, CEAL.

- Pascucci, S. (2007) Costureras, monjas y anarquistas. Trabajo femenino, Iglesia y lucha de clases en la industria del vestido (Buenos Aires, 1890-1940). Buenos Aires, Ediciones RyR.

- Pineau, P. (1991) Sindicatos, Estado y educación técnica (1938-1968). Buenos Aires, CEAL.

- Plotkin, M. (1995) Mañana es San Perón. Propaganda, rituales políticos y educación en el régimen peronista, 1946-1955. Buenos Aires, Ariel.

- Puiggrós, A. y Bernetti, J. L. (2003) Peronismo: cultura política y educación (1945-1955). Buenos Aires, Galerna.

- Santos Martínez, P. (1979) La nueva Argentina, 1946-1955, Tomo I, Buenos Aires.

- Suriano, J. (2007) "El trabajo infantil", en Torrado, S. Población y bienestar en la Argentina del primero al segundo centenario, Tomo 2, Buenos Aires, Edhasa.

- Suriano, J. (1990) "Niños trabajadores. Una aproximación al trabajo infantil en la industria porteña a principios de siglo", en Armus D. (comp.) Mundo urbano y cultura popular. Buenos Aires, Sudamericana.

- Tedesco, J. C. (1980) La educación en argentina. (1930-1955). Buenos Aires, CEAL. 
- Weimberg, G. (1985) El descontento y la promesa. Buenos Aires, Editorial de Belgrano.

- Wiñar, D. (1979) Poder político y educación: el peronismo y la CNAOP, Buenos Aires, ITDT.

\section{Fuentes}

- Anales de legislación argentina (1953). Complemento, año 1920-1940, (1953). Buenos Aires, Editorial La Ley.

- Anales de Legislación Nacional, (1943) Tomo II / (1945), Tomo V. Buenos Aires, Editorial La Ley.

- $\quad$ Argentina Fabril, (1940) Año LIII, № 855 y No 859, (1941), Año LIV, № 868, (1942) LV, No 876 y 882, (1943), Año LVI, Nº 891, 894 y 897.

- $\quad$ El obrero del calzado: (1939) $\mathrm{N}^{\circ} 40$, (1940) $\mathrm{N}^{\circ} 42$, (1941) $\mathrm{N}^{\circ} 44,(1943)$ $\mathrm{N}^{\circ} 53$.

- La industria argentina del calzado: febrero de 1940, marzo de 1944, mayo de 1946 y agosto de 1947.

- Ministerio de Justicia e Instrucción Pública (1935) Escuelas de Artes y Oficios. Informe elevado por intermedio de la Inspección General de Enseñanza, del inspector de esos establecimientos, Ing. Juan José Gómez, Buenos Aires.

- Ministerio de Justicia y Educación (1935) Creación, fundación, organización y plan de estudios de cuatro escuelas técnicas de oficios, Buenos Aires.

- Revista de la Unión Industrial Argentina (1944) Año LVII, Nº 904, 908 Y 909, (1945) Año LVIII, N No 916. 